\title{
Deep venous thrombosis induced by intravenous thrombogenic drugs
}

\author{
Chito Singh T. ${ }^{1}$, Chinglensana L. ${ }^{2 *}$, kumar Singh Salam S. ${ }^{3}$, Priyabarta Singh Y. ${ }^{4}$, Mackson N. ${ }^{5}$ \\ DOI: https://doi.org/10.17511/ijmrr.2020.i01.13 \\ 1 Thokchom Chito Singh, Associate Professor (CTVS), Department of Surgery, Regional Institute of Medical Sciences, Imphal, Manipur, \\ India. \\ 2* Laitonjam Chinglensana, Assistant Professor, Department of Surgery, Regional Institute of Medical Sciences, Imphal, Manipur, India. \\ 3 Sunil kumar Singh Salam, Assistant Professor, Department of Surgery, Regional Institute of Medical Sciences, Imphal, Manipur, India. \\ ${ }^{4}$ Yumnam Priyabarta Singh, Assistant Professor, Department of Surgery, Regional Institute of Medical Sciences, Imphal, Manipur, India. \\ 5 Nongmaithem Mackson, Senior Resident, Department of Surgery, Regional Institute of Medical Sciences, Imphal, Manipur, India.
}

Background: Deep vein thrombosis (DVT) is a major preventable cause of morbidity and mortality worldwide with the potential to cause dreaded pulmonary embolism (PE). Disease and patientspecific considerations are preferably incorporated into therapeutic options for effective management. Materials and methods: Sixty-eight cases of acute deep vein thrombosis were treated within a period of 3 years from January 2016. All the cases were subjected to routine investigations with the Doppler study of the affected limb. Low molecular weight heparin (dalteparin) was administered in all the cases for a period of 15 days and Doppler study was repeated at the end of the drug therapy. After the course of low molecular weight heparin, the patients were given acenocoumarol $2 \mathrm{mg}$ daily. Estimation of partial thromboplastin time and prothrombin time were performed before starting and during the treatment of the low molecular weight heparin and acenocoumarol regularly. Venogram was done only when the repeated Doppler study revealed unsatisfactory response to low molecular weight heparin therapy. Eight cases underwent thrombectomy and postoperative period was uneventful. Results: Age group of 21-30 years was most affected $(80.8 \%)$ with right lower limb being the commonest affected site of injection and associated lesions. Conclusion: DVT in young population remains a challenge to the evaluating clinician. A variety of disease states can alter the anticoagulant factors. Urgent diagnosis and appropriate intervention carries paramount importance.

Keywords: Venous thrombosis, Prothrombin time, Thrombophlebitis, Intravenous drug user

\section{Corresponding Author}

Laitonjam Chinglensana, Assistant Professor, Department of Surgery, Regional Institute of Medical Sciences, Imphal, Manipur, India. Email: chinglensana@rediffmail.com
How to Cite this Article

To Browse

Singh TC, Chinglensana L, Salam SKS, Singh YP, Mackson N. Deep venous thrombosis induced by intravenous thrombogenic drugs. Int J Med Res Rev. 2020;8(1):86-91.

Available From

https://ijmrr.medresearch.in/index.php/ijmrr/article/ view/1129

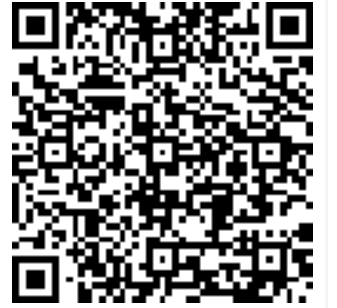

Manuscript Received 2020-01-04

Conflict of Interest No
Review Round 1 2020-01-10

Funding

$\mathrm{Nil}$
Review Round 2 2020-01-14

Ethical Approval Yes
Review Round 3

Accepted 2020-01-18

(c) 2020 by Thokchom Chito Singh, Laitonjam Chinglensana, Sunil kumar Singh Salam, Yumnam Priyabarta Singh, Nongmaithem Mackson and Published by Siddharth Health Research and Social Welfare Society. This is an Open Access articl
licensed under a Creative Commons Attribution 4.0 International License https://creativecommons.org/licenses/by/4.0/ unported [CC BY 4.0]. 


\section{Introduction}

Deep vein thrombosis is a common yet often underrecognized condition especially among hospitalized patients. Although most thrombi in legs are small, asymptomatic and confined to deep veins, $20 \%$ of these calf vein thrombi extend into the proximal deep veins and can lead to fatal pulmonary embolism. The clinical features of deep vein thrombosis are swelling, pain, redness or no apparent signs and symptoms, dilated superficial vein, calf tenderness and low grade of pyrexia. Deep vein thrombosis may present as a painful swollen leg or arm or may be entirely asymptomatic. It is also common among intravenous drug users. The incidence of HIV sero-positivity among injecting drugs users is very high in the state of Manipur, India. The sentinel survey conducted in Manipur in February - March 1997 showed that the HIV seroprevelence among injecting drugs users was $80.70 \%$ as compared with $55 \%$ during 1995 [1]. They commonly used antispasmodic (composed of dicyclomin HCL- $10 \mathrm{mg}$, dextropropoxyphene-65mg and acetaminophene-40mg) is the mainly abused drug in northeast region of India. It produces acute septic deep vein thrombosis following injection. Acute deep vein thrombosis in intravenous drug users is a potentially a life threatening condition. The research article is our experience in the management of drug induced deep vein thrombosis in Regional Institutes of Medical Sciences Hospital, Imphal, Manipur.

\section{Materials and Methods}

The primary aim was a observational study of all cases of deep venous thrombosis induced by intravenous drugs who were admitted and treated during 3 years from January 2017 to December 2019 at Cardiovascular and Thoracic Surgery, Department of Surgery, Regional Institute of Medical Sciences, Imphal, a tertiary care hospital in Northeast India. The study includes patients referred from Department of Surgery, Medicine, Orthopaedics and State hospitals of Manipur. 20 patients among the study group resulted from injection of solution-prepared antispasmodic tablets. The mean duration of using the prepared solution was 2 years with the range of 1-3 years. Inclusion criteria were all cases with DVT resulting from intravenous drug administration or abuse registered with the hospital. Exclusion criteria were those with recent intracranial or gastrointestinal bleed, pregnancy, uncontrolled hypertensive patients and
Cases without any history of intravenous drug administration. Ethical clearance was obtained from the Hospital Ethics Committee of the Institute.

Table-I: Age distribution among the patients admitted with DVT.

\begin{tabular}{|l|l|l|}
\hline \multicolumn{3}{|c|}{ Age group (in years) } \\
\hline $10-20$ & $21-30$ & $31-40$ \\
\hline $6(8.8 . \%)$ & $55(80.9 \%)$ & $7(10.3 \%)$ \\
\hline
\end{tabular}

Table-II: Limb selection for intravenous drug abuse among the patients.

\begin{tabular}{|l|l|l|l|}
\hline \multicolumn{4}{|c|}{ Site of injection } \\
\hline Upper Limb & Lower Limb \\
\hline Right & Left & Right & Left \\
\hline $4(5.8 \%)$ & $1(1.5 \%)$ & $42(61.8 \%)$ & $21(30.9 \%)$ \\
\hline
\end{tabular}
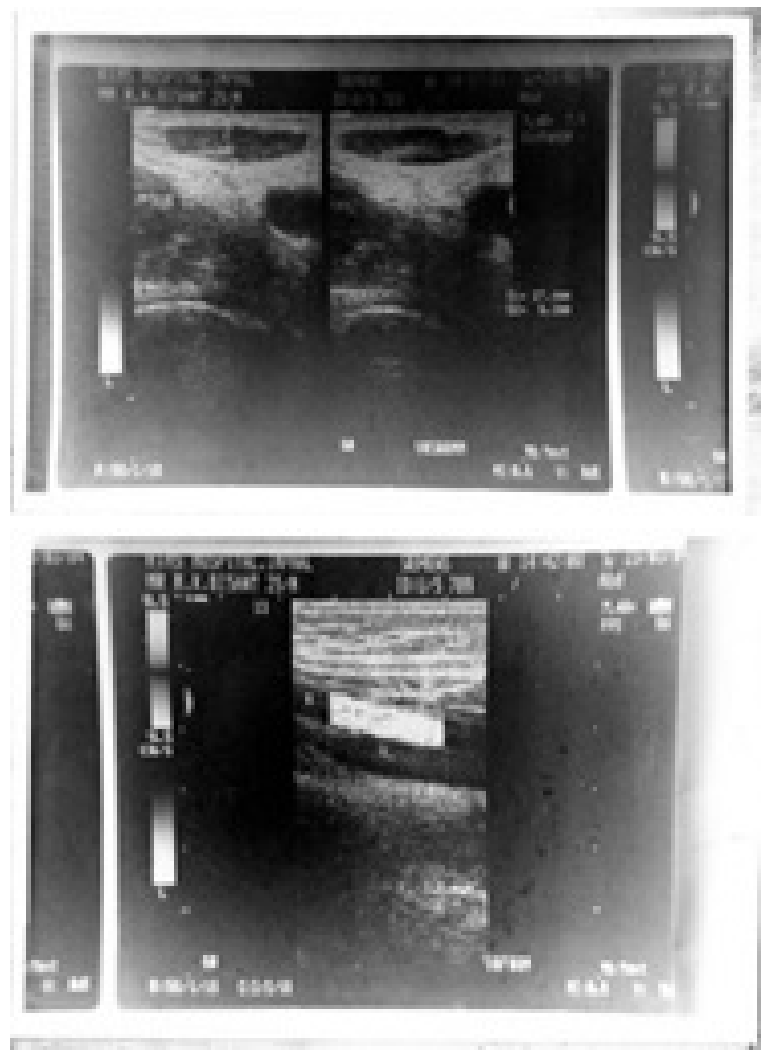

Fig-1: Doppler study of the venous thrombosis affected lower limb patient

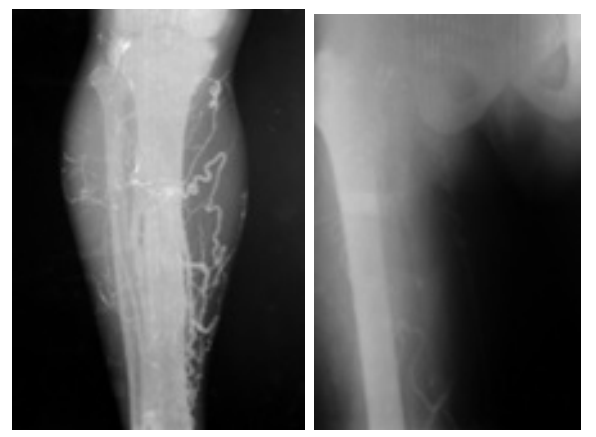

Fig. 2. Venogram of the lower limb 


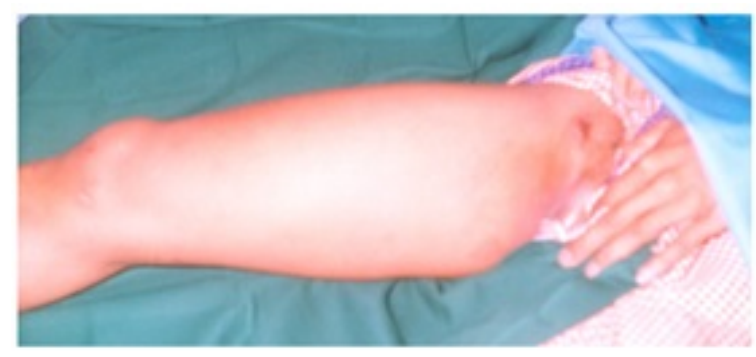

Fig.3: Deep venous thrombosis of lower limb (left) with injection site inguinal abscess.

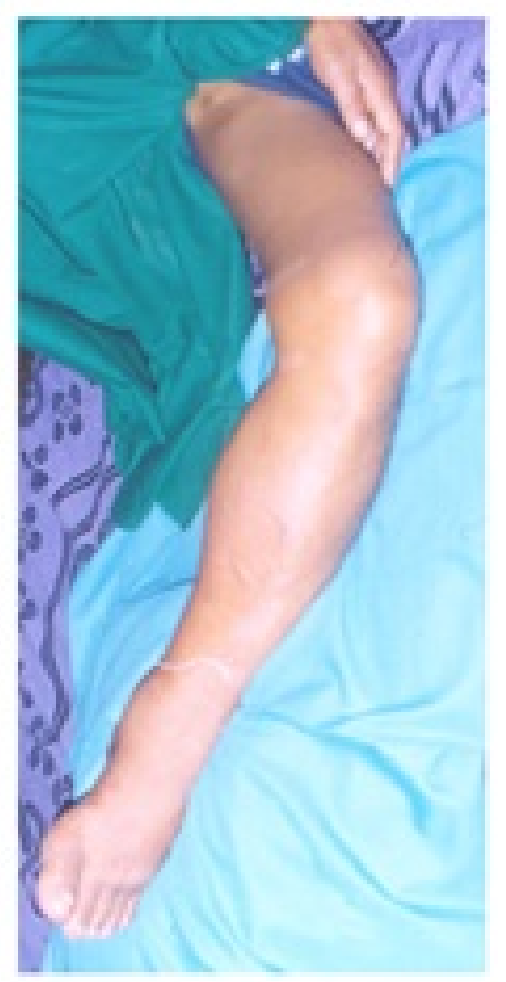

Fig.-4: Deep venous thrombosis of lower limb (right) with distal thrombophlebitis.

Data collections including all the routine investigations of blood, retrovirus/human immunedeficiency virus test (HIV), hepatitis B virus, hepatitis $\mathrm{C}$ virus, C-reactive protein, prothrombin time and partial thromboplastin time were performed in all the patients. In some of the patients with severe pyrexia blood culture was done. Retrovirus/HIV test and blood culture were positive in eight and six cases respectively. The Doppler study of the affected lower limb was performed in all the patients and it was found to be positive in all deep vein thrombosis cases (Fig. 1). Ultrasound of the lower abdomen, $X$ - ray chest postero-anterior view was also performed in all the cases. Venogram was done in six cases (Fig. 2). Culture and sensitivity from the associated case of inguinal abscess and wound infection were found to
Have presence of staphylococcus, pseudomonas and klebsiella species. The maximum numbers of cases were found in the age groups of 20 to 30 years (Table-I). All the cases were males. Usually the solution was injected by a hypodermic syringe at femoral vein, cubital vein, medial thigh etc. Fortytwo patients had injection on the right lower limb, another twenty-one cases were injected on the left lower limb and four cases had injection on right upper limb and one case on left upper limb (TableII). Some of the patients were found to have associated complications at the site of injection resulting in inguinal abscess in some cases (Fig 3), wound infection of foot in one case and thromboplebitis in three cases (Fig 4).

Mechanism of action of main offending antispasmodic drug which has the following composition are:

01. Dicyclomine Hydrochloride $10 \mathrm{mg}$ : It is a tertiary amine synthetic compound having anticholinergic, antisecretory, antiemetics and antispasmodic properties. Prophylactically, its used in motion sickness and morning sickness in the dose of $10-20 \mathrm{mg}$ orally. It has no teratogenic potential.

02. Dextropropoxyphene $65 \mathrm{mg}$ : It is synthetic opioid, chemically related to methadone but quite similar in analgesic action to codeine. It is half as potent as codeine and metabolized in liver. Demethylated metabolites are cardiotoxic and causes delirium and convulsion in overdose. It also causes irritation on parenteral administration. It is used orally in the dose of $60-120 \mathrm{mg}$ in combination with aspirin and paracetamol.

03. Acetaminophen $400 \mathrm{mg}$ : It is a Para-amino phenol derivative having anti-inflammatory and antipyretic properties. It is used in mild to moderate pain.

\section{Results}

Treatment of deep vein thrombosis is initiated as soon as the diagnosis is suspected. However, it is given as supportive treatment when the patient is having oedema of the lower limb. Occasionally, massive venous thrombosis in the lower limb leads to severe impairment in the blood supply to the limb, leading to ischaemia and eventually gangrene. This is a surgical emergency and requires rapid relief of the venous obstruction. This can be achieved surgically by opening the femoral vein via 
An incision in the groin and removing all clots from the deep veins of the leg and pelvis. This operation is widely performed on the assumption that it would reduce the severity of post-thrombotic vein damage following deep vein thrombosis. In our treatment, eight patients underwent venous thrombectomy by using 7F Fogarty venous thrombectomy catheter. In both the cases, femoral vein were opened below the inguinal ligament under spinal anesthesia. The catheter was introduced inside the vein and passed down upto the region of medial malleolus and balloon inflated. The thrombus was removed by gradual withdrawal of the inflated balloon. The procedure was repeated till the thrombus and blood clots were cleared from the lumen of vessel. After completing removal of thrombus from the distal portion, the proximal portion of the vein was also explored to rule out any extension of thrombus proximally. Washing of the lumen of femoral vein was done with heparinised saline. After completing the procedure femoral vein was closed with 5-0 prolene suture. In the postoperative period, the limb was kept in elevated position and started mobilization on the same night of the operation day. In all of the patients, there were no complications and postoperative period was uneventful. The mean hospital stay was 20 days.

\section{Discussion}

Intravenous drug users related human immunodeficiency virus (HIV) infection is very common in Manipur. There are about 15,000 to 20,000 intravenous drug abusers in Manipur [1]. People with HIV infection are more susceptible to thrombotic events. Venous thromboembolism occurs frequently in HIV infected person but arterial thrombosis has only rarely been reported [2]. Less frequently cytomegalovirus has been implicated in the development of thrombosis [3]. HIV/AIDS (Acquired Immuno-deficiency syndrome) infection is a considerable risk for development of deep vein thrombosis in the lower extremity. Statistically deep vein thrombosis in HIV/AIDS is approximately 10 times greater than in the general population [4]. Despite various HIV related factor have been proposed as potentially thrombogenic, HIV related hypercoagulability has been suggested as important factor for thrombogenic in HIV infected patient [5]. Therefore, AIDS patient should be alert to the possibility that venous thromboembolism may complicate HIV infection. In intravenous drug users skin or subcutaneous abscesses and suppurative thrombophlebitis of small veins are well recognized
Complications after unsterile and usually unsuccessful attempts to gain access to peripheral vessels [5]. In our study, there were 20 cases of acute deep vein thrombosis following intravenous use of antispasmodic drug with unsterile diluents solution. The patients usually give history of injection of solution-prepared antispasmodic tablet frequently for the previous 2-3 years. The maximum age group was found between 20-30 years. They usually present with swelling of the lower limbs, pain and injecting scar marks. The diagnosis was made by color Doppler ultrasound of the lower limbs. The value of early intravenous heparin followed by oral anticoagulation in patient with septic thrombosis remains controversial [6]. For superficial suppurative thrombophlebitis surgical excision has been recommended as an integral part of treatment [7]. In our study, no surgical excisions of the superficial abscess at the site of injection were done. In patient with intravenous catheter related septic deep vein thrombosis, resection or ligation of the involved veins or thrombectomy with removal of the infected part has been reported to be helpful after unsuccessful conservative therapy [8]. However, surgical therapy is only rarely necessary in intravenous drug user with septic thrombosis. Ang and Brown study also found that venous thrombectomy is unnecessary, antibiotic and anticoagulation therapy are adequate treatment [9]. In the treatment of deep vein thrombosis in associated with human immunodeficiency virus infection, palliative measures and low dose intravenous heparin were successfully employed [10]. But, Garrison et al., found that septic thrombophlebitis is best prevented by strict asepsis in catheter placement and rotation of infusion sites every 48 hours and total excision of the infected vein remains the treatment of choice [11]. In septic non-suppurative thrombophlebitis study by Zinner et al, there was failure of antibiotic to the organism until involved vein was excised [3]. In our case, thrombectomy was performed in eight cases, which showed good results and postoperative period was uneventful. Overall, the analysis of results showed low molecular weight heparin in combination with appropriate antibiotics has high efficacy in patients with deep vein thrombosis. The patients with failure to respond to low molecular weight heparin should undergo venogram. If localized thrombus is present in venogram then surgery is indicated, either excision of the involved vein or thrombectomy. Deep vein thromboses are common in users of intravenous drugs and recognised as an important 
Problem among healthcare workers who treat drug users. There is limited published research on the problem more so on the illicit use of thrombogenic drugs and solution-prepared injections of orally used tablets which predispose individuals to DVT. Once users of intravenous drugs have been diagnosed with DVT, their concordance with treatment regimes in community settings is unreported and potentially problematic [12]. Venous access to monitor coagulation is difficult in many patients because of damage caused to veins from repeated drug use. As regular attendance which is necessary when medications such as warfarin are prescribed is likely to be compromised in users of intravenous drugs, many professionals offer selfadministered heparin injections and this method reduces the problem of attendance [13] but does not necessarily ensure regular, reliable administration. Intravenous drug-related DVT has substantial resource implications for the healthcare system. In one published study of 182 females aged 16-70 years who were admitted to hospital with DVT, the cause of DVT in $20 \%$ of cases was intravenous drug use this figure rose to $52 \%$ for those aged less than 40 years [12]. In a further study of 109 patients presenting to an emergency department with possible DVT, a third were users of intravenous drugs [14]. DVTs resulting from intravenous drug use differ in a number of ways from those arising from other causes. They are likely to be situated in the femoral vein more commonly the right than the left [15]. Such site selection is probably easier to diagnose clinically [14]. Intravenous drug use is more likely to be the cause of DVT in younger patients who are more likely to be admitted and have longer hospital stays [14]. The aetiology of DVT in the general population are varied and possibilities includes blood hypercoagulability, stasis, blood-vessel injury, and anoxic damage to venous valves [16]. The aetiological factors in users of intravenous drugs are likely to be different and possible causes include reduced blood flow from inactive muscle pumps during periods of intoxication, endothelial damage from injections, and elevated coagulation factors from infection introduced through injections [17]. 3 months of anticoagulation is now established as the optimum treatment for patients with DVT who have an $8 \%$ chance of developing further DVT or pulmonary emboli over 1 year $[18,19]$. There is a lack of evidence about the risk of long-term complications and the optimum treatment approach for DVT resulting from intravenous drug use. Taking
Anticoagulants carries more risk if intravenous drug use is continuing. There has been no systematic study of post-thrombotic complications following DVT in users of intravenous drugs; however, longterm complications are significant in people who do not use drugs [20] and complications among some patients may be prevented by measures such as exercise [21]. Associating a single risk factor for thrombosis in DVT cases is very difficult. Cases such as surgery and prolonged immobility especially amongst orthopaedic referrals included in this study might have additional propensity towards DVT development. Even though there was no significant difference between the incidence rate of the disease during the 3 years of study, the prevalence of this complication among those hospitalised in other centres would give a fuller picture. The rising trend of DVT can occur for many other reasons and its risk factors are usually multiple. Lengthy trips and air travels, use of oral contraceptive pill (OCP), increasing the number of surgeries and immobilisation are just a few amongst many.

\section{Conclusion}

Deep vein thrombosis is very common amongst intravenous drug users. Low molecular weight heparin has high efficacy in the management of deep vein thrombosis. Surgery is indicated if ischaemia and gangrene develops from the localized thrombus after intravenous injection. The recognition of DVT cases has become more accurate in recent years with the increasing ability to detect the disease early and the arrival of new diagnostic aids. The emergence of a range of other risk factors such as the treatment of hormone replacement therapy, the widespread use of contraception are influential in increasing the incidence of DVT other than those induced by intravenous thrombogenic drugs.

\section{Reference}

01. Singh I. Integrated Rapid Intervention and Care Project (RIAC) Manipur, RIAC Guideline Booklet Manipur State AIDS Control Society Research and Development Wing. Lamphelpat, Imphal-4, 2nd Edition. 2004;Jan;pp1-16.

[Crossref]

02. Callen S, Florence E, Phillippe M, Van Der Plank -en M, Colebunders R. Mixed arterial and venous thromboembolsm in a person with HIV infection. Scand J Infect Dis. 2003;35(11-12)907-8. [Crossref] 
03. Zinner MJ, Zuidema GD, Lowery BD. Septic nonsuppurative thrombophlebitis. Arch Surg. 1976; Feb; 111(2)122-5.

[Crossref]

04. Saber AA, Aboolian A, LaRaja RD, Baron $H$, Hanna K. HIV/AIDS and the risk of Deep Vein Thrombosis- a study of 45 patients with lower extremity involvement. Am Surg. 2001;]ul; 67(7)645-7.

[Crossref]

05. Fah F, Zimmerli W, Jardi M, Ronal AS. Septic Deep Venous Thrombosis in Intravenous Drug Users. Swiss Med Wely. 2002,132;386-392. [Crossref]

06. Stein JM, Pruitt BA. Suppurative thrombophlebitis a lethal iatrogenic disease. $\mathrm{N}$ Engl K Med. 1970,282;1452-5.

[Crossref]

07. Niemeyer HW, Grabitz K, Buhl R, Wust HJ, Sandmann W. Surgical treatment of septic deep venous thrombosis. Surg. 1995,118;49-53. [Crossref]

08. Munster AM. Septic thrombophlebitis a surgical disorder. JAMA. 1974,230;1010-11.

[Crossref]

09. Ang AK, Brown OW. Septic Deep Vein Thrombosis. J Vascular Surg. 1986;Dec-4 (6)563-6.

[Crossref]

10. Tanimowo M. Deep Vein Thrombosis as a manifestation of the acquired immunodeficiency syndrome?- A case report. Cent Afr J Med. 1996;Nov-42(11)327-8.

[Crossref]

11. Garrison RN, Richardson JD, Fry DE. Catheter associated Septic Thrombophlebitis. Southern Medical J. 1982;Aug-75(8)917-9.

[Crossref]

12. McColl MD, Tait RC, Greer IA, Walker ID. Injecting drug use is a risk factor for deep vein thrombosis in women in Glasgow. $\mathrm{Br}$ J Haematol. 2001;112(3)641-643.

[Crossref]

13. Russell M, Dawson D. Best evidence topic report- Low molecular weight heparin for intravenous drug users with deep vein thrombosis. Emerg Med J. 2004;21(6)711.

[Crossref]
14. Cooke VA, Fletcher AK. Deep vein thrombosis among injecting drug users in Sheffield. Emerg Med J. 2006;23(10)777-779.

[Crossref]

15. Syed FF, Beeching NJ. Beeching Lower-limb deep-vein thrombosis in a general hospital risk factors, outcomes and the contribution of intravenous drug use. QJM. 2005;98(2)139145.

[Crossref]

16. Malone PC, Agutter PS. The aetiology of deep venous thrombosis. QJM. 2006;99(9)581-593.

[Crossref]

17. Mackenzie AR, Laing RB, Douglas JG, et al. High prevalence of iliofemoral venous thrombosis with severe groin infection among injecting drug users in North East Scotland successful use of low molecular weight heparin with antibiotics. Postgrad Med J. 2000;76(899)561-565.

[Crossref]

18. Campbell IA, Bentley DP, Prescott RJ, et al. Anticoagulation for three versus six months in patients with deep vein thrombosis or pulmonary embolism, or both- randomised trial. BMJ. 2007;334(7595)674.

[Crossref]

19. Boutitie F, Pinede L, Schulman S, et al. Influence of preceding length of anticoagulant treatment and initial presentation of venous thromboembolism on risk of recurrence after stopping treatment- analysis of individual participants' data from seven trials. BMJ. $2001 ; 342 ; \mathrm{d} 3036$.

[Crossref]

20. Kahn SR, Ducruet T, Lamping DL, et al. Prospective evaluation of health-related quality of life in patients with deep venous thrombosis. Arch Intern Med. 2005;165(10)1173-1178. [Crossref]

21. Shrier I, Kahn SR. Effect of physical activity after recent deep venous thrombosis- a cohort study. Med Sci Sports Exerc. 2005;37(4)630634.

[Crossref] 